\title{
Effect of Experiential Learning on Self-Esteem, Resilience and Tolerance for Disagreement
}

\author{
Ms. Milli Baby ${ }^{1 *}$
}

\section{ABSTRACT}

This paper attempts to explore the role of experiential learning in groups on the participants Selfesteem, Resilience and Tolerance for disagreement. Sample consisted of undergraduate students $(\mathrm{N}=41)$ from a seminary located in Nagpur. The Pre-test result showed that over all, initial participant's responses fell within the normal ranges for self-esteem, resilience and tolerance for disagreement. Paired t test were computed for $(\mathrm{N}=41)$ who completed both the pre-test and posttest. These comparisons show a significant increase in means of self esteem, resilience and tolerance for disagreement scores. This increase indicates the importance of team-building workshop having recreation activities, games and exercises.

Keywords: Self-Esteem, Resilience And Tolerance For Disagreement

Groups are a part of social and organizational life. Whenever two or more people come together to achieve certain objectives and interact and work interdependently, it is a group. It has been observed that individuals work and behave quite differently when working in the groups than when working alone. Theorists suggest two basic features that define a group:

1. Members of a group interact with each other. Every person's behaviour influences and is influenced by another person's behaviour/action.

2. Members of a group perceive that by joining the group there is potential for mutual goal achievement i.e., group provides opportunity to attain certain goals satisfy certain needs.

People bring a variety of needs to organizations and groups cater, to many of these psychological needs.

\footnotetext{
${ }^{1}$ Assistant Professor, Department of Psychology, Vasantrao Naik Govt. Institute of Arts and Social Sciences, Nagpur, India

*Responding Author

(C) 2016, M Baby; licensee IJIP. This is an Open Access Research distributed under the terms of the Creative Commons Attribution License (http://creativecommons.org/licenses/by/2.0), which permits unrestricted use, distribution, and reproduction in any Medium, provided the original work is properly cited.
} 


\section{THE VARIABLES IN THE STUDY}

\section{Self-esteem}

Self-esteem is a socio-psychological construct that assesses an individual's attitudes and perceptions of self-worth. Self-esteem is an understanding of one's quality as an object- that is, how good or bad, valuable or worthless, positive or negative, or superior or inferior one is (Thoits, 1999). Self-esteem refers to the extent to which a person believes him/herself to be capable, significant, worthy, successful, and the extent to which a positive or negative attitude is held toward the self (Coopersmith, 1967: Kling, Hyde, Showers, \& Buswell, 1995).

A person with high self-esteem is more likely to view an insecure work situation as challenging than as threatening, and therefore avoid experiencing job insecurity. In addition, (Brockner, 1988) has advanced the hypothesis by claiming that persons with low self-esteem are generally more susceptible to environmental and, in particular, organizational events than are persons with high self-esteem. (Ryff, 1999) proposes that some factors of well-being-in particular, selfacceptance, environmental mastery and purpose in life-are highly correlated with self-esteem.

\section{Resilience}

American Psychological Association (APA) suggests that resilience is the process of adapting well in the face of adversity, trauma, tragedy, threats, or even significant sources of stress - such as family and relationship problems, serious health problems, or workplace and financial stressor. It means "bouncing back" from difficult experiences. Resilience is not a trait that people either have or do not have. It involves behaviors, and actions that can be learned and developed in anyone. Factors contributing to resilience include (a) having caring supportive relationships within and outside the family, (b) the capacity to make realistic plans and take steps to carry them out, (c) a positive view of yourself and confidence in your strengths and abilities, (d) skills in communication and problem solving, and (d)the capacity to manage strong feelings and impulses. All of these are factors that people can develop in them.

\section{Tolerance for Disagreement}

Conflict between people is a common feature of the human condition. When people interact and form relationships, disagreements inevitably emerge. A plethora of research has been conducted on the nature of conflict (Coser, 1956; Fisher, 1970; Horney, 1937; Kilmann \& Thomas, 1977; Mack, 1966; Watkins, 1974). However these studies have often failed to differentiate between conflict leading to negative interpersonal outcomes and purposeful disagreement which often lead to better decisions and other positive outcomes. Although disagreement is common, its result does not have to be destructive. Disagreement can be and frequently is constructive (Coser, 1956; Deutsch, 1973). Whether the results are constructive or destructive often depends on the communication skills of the individuals and the affinity between them. 


\section{Effect of Experiential Learning on Self-Esteem, Resilience and Tolerance for Disagreement}

The tolerance for disagreement scale is designed to measure the degree to which an individual can tolerate other people disagreeing with what the individual believes to be true. This conceptualization is similar to that of argumentativeness. People with high argumentativeness are likely to be able to deal with more disagreement than those people who are low in argumentativeness.

\section{T-Group training: The experiential learning}

A T-group (the ' $\mathrm{T}$ ' stands for training) is a group activity in which you give and receive feedback about emotional (and other) reactions to one another. Participants learn about how they are read about by others and a lot about interpersonal dynamics in general. This enables participants to better understand their own way of functioning in a group and the impact they have on others which would permit them to become more competent in dealing with difficult interpersonal situations.

Important aspects of group sessions are to provide a safe environment in which to foster a level of trust between participants, so that they may talk personally and honestly to and about themselves to each other.

Sources of change in groups: The participants in a group setting are likely to experience some changes, which may be based on the following: (a) self-observation- participants give more attention to their own intentions, feelings, etc. (b) feedback- participants receive information on the impact they have own others, (c) insight- participants expand self-knowledge, (d) selfdisclosure- participants expose more of themselves to others, (e) universality- participants experience that others share their difficulties, concerns or hopes, (f) group cohesion- participants experience trust, acceptance and understanding, (g) hope- participants see others learn, achieve their goals, improve, and cope more effectively, (h) vicarious learning- participants pick up skills and attitudes from others, and (i) catharsis- participants experience a sense of release or breakthrough.

The conceptual scheme was founded on the following:

First, social identity theory offers explanation for group formation. This theory suggests that individuals get a sense of identity and self-esteem based upon their membership in salient groups. The nature of the group may be demographically based, culturally based, or organizationally based. Individuals are motivated to belong to and contribute to identity groups because of the sense of belongingness and self-worth membership in the group imparts. It was hypothesized that self-esteem will increase due to group experiential learning.

Second, resilience is not a trait that people either have or do not have. It involves behaviors, thoughts, and actions that can be learned and developed in anyone. Therefore, it is an important variable if it contributes to well-being because it is amenable to change through learning, training 


\section{Effect of Experiential Learning on Self-Esteem, Resilience and Tolerance for Disagreement}

and development, even through self-development. Since resilience is the process of adapting well in the face of adversity, it was hypothesized that experiential learning in group will significantly increase the magnitude of resilience and that to collective resilience.

Third, McCroskey and Wheelers(1976) employed the concept of "tolerance for disagreement" to help them explain the threshold individuals have for dealing with interpersonal conflict. They maintained that conflict and disagreement are not the same thing. Disagreement can be thought of as simple difference of opinion. However, disagreement does not necessarily lead to conflict. Rather than disagreement necessarily triggering conflict, McCroskey and Wheelers argued that what triggers people to enter into conflict is a low degree of affinity between them, in the presence of disagreement on some issue. With an increase in affinity that trigger might not be activated.

The workshop was developed so as to improve the self esteem, resilience and tolerance for disagreement among the participants. The workshop was 20 hours of supervised activities on chosen topics of group dynamics

With this theory as a base the following study was conducted in which 41 students of BA I coming from different parts of India to become priests staying in Seminary was selected. Facilitator led two sessions of two and a half hour each for a week.

Each session was designed to facilitate dialogue and to produce an inclusive environment that fostered self-reflection and ownership. Significant input from the participants was required and the facilitator was responsible for ensuring that respect for the opinions of all participants was accomplished through nonjudgmental listening, honoring their experiences, and creating an atmosphere of acceptance. Five ground rules were established during the sessions:

1. Everyone must agree to a code of confidentiality and abstain from repeating anything that is discussed during the sessions.

2. Everyone must participate in discussions and complete the task.

3. Everyone must listen and must not talk over another'

4. Everyone must abstain from laughing at, teasing, or criticizing one another.

5. Everyone must be honest.

Over the course of ten sessions, participants had the opportunity to engage in role-play, exercises, to complete test, to make a presentation in front of the class about their goals, to learn about ways of decision making and conflict resolution in groups, and to work together in groups.

\section{Hypotheses and Research Questions}

The central hypothesis of the study was that students in the group would significantly increase; their self-esteem score, total resiliency score and their tolerance for disagreement score. 
Effect of Experiential Learning on Self-Esteem, Resilience and Tolerance for Disagreement

\section{Research Questions}

1. Will there be significant difference between student's level of self-esteem immediately before and immediately after the group's experiential training, as self-esteem is conceptualized to be functioning to be as a trait and thus may remain invariant across time.

2. Will there be significant difference between student's level of resilience immediately before and immediately after the group's experiential training.

3. Will there be significant difference between student's tolerance for disagreement immediately before and immediately after the group’s experiential training.

\section{METHOD}

\section{Sample}

The sample consisted of 41 male undergraduate students belonging to a Christian institution located in Nagpur [(Mean age $=20$, SD age $=0.81$ (Minimum age 18, Maximum age 22)]. All the students in the sample were participating in a week long course in which experiential learning in a T- group is required.

\section{Measures}

Self-esteem: Self-esteem was measured through a 10 point questionnaire with a 4 point scale which was based on Rosenberg (1985).

Resilience: Wagnild and Young's (1993) 25-item, 7 point scale, psychological resilience scale was used.

Tolerance for disagreement: Measured by the 15- items, 5 point scale, by Teven, J. J., Richmond, V. P., \& McCroskey, J. C.

\section{Procedure}

The data were collected through structured questionnaires on two time points, with the gap of a week in between. The respondents were participating in a course on group dynamics in which experiential learning in a T-group typesetting in required. The respondents belonged to an institute which maintains a very high level of academic pressure and discipline. Such a high pressure environment exerts influences on a number of psychological variables, like resilience and self esteem. This being a residential institution the participants tend to develop affinity which effects tolerance for disagreement, the pre-test data were collected through structured questionnaire from the respondents on the variables included in the study. After which the experiential training started and went on for a week. Then the post-test data were obtained from the same set of rspondents.41 respondents participated who was all male.

\section{RESULTS}

Mean and standard deviation of self esteem scores of the participants of pre and post test are shown in Table 1. It indicates the effect of experiential training given to the group. It shows the 
difference between the same group pre and post training was statistically significant $t$-value, $(t=$ 4.11, $p<.01)$.

Table 1: Mean, SD of Pre and Post test over Self-esteem

\begin{tabular}{|l|l|l|l|l|}
\hline & N & Mean & SD & $\begin{array}{l}\text { (40) pre and } \\
\text { post test }\end{array}$ \\
\hline Pre $(\mathrm{M})$ & 41 & 18.43 & 4.27 & $4.11^{* *}$ \\
\hline Post $(\mathrm{M})$ & 41 & 20.36 & 4.03 & \\
\hline${ }^{* * p} p<.01$ &
\end{tabular}

Table 2: Mean, SD of Pre and Post test over Resilience

\begin{tabular}{|l|l|l|l|l|}
\hline & N & Mean & SD & $\begin{array}{l}\text { t (40) pre and } \\
\text { post test }\end{array}$ \\
\hline Pre $(\mathrm{M})$ & 41 & 125.56 & 19.35 & $3.12^{* *}$ \\
\hline Post(M) & 41 & 134.51 & 15.32 & \\
\hline${ }^{* * p<.01}$ &
\end{tabular}

Table 3: Mean, SD of Pre and Post test over Tolerance for disagreement

\begin{tabular}{|l|l|l|l|l|}
\hline & N & Mean & SD & $\begin{array}{l}\text { t (40) pre and } \\
\text { post test }\end{array}$ \\
\hline Pre $(\mathrm{M})$ & 41 & 46.48 & 7.65 & $6.40^{* *}$ \\
\hline Post $(\mathrm{M})$ & 41 & 48.19 & 6.58 & \\
\hline
\end{tabular}

$* * p<.01$

Mean and standard deviation of Resilience scores of the participants of pre and post test are shown in Table 2. It indicates the effect of experiential training given to the group. It shows the difference between the same group pre and post training which was statistically significant, $t$ value $(t=3.12, p<.01)$.

Mean and standard deviation of tolerance for disagreement scores of the participants of pre and post test are shown in Table 3. It indicates the effect of experiential training given to the group. It shows the difference between the same group pre and post training was statistically significant, $t$ value $(t=6.40, p<.01)$.

\section{DISCUSSION}

\section{Self-esteem}

Significant increase in the self esteem of the participants after the experiential training validates the hypothesis. Students with high self esteem often show increased academic performance, improved health, and more productive behaviors; on the other hand low-self esteem in students has been linked to poor academic achievement, depression, smoking and other deleterious social 


\section{Effect of Experiential Learning on Self-Esteem, Resilience and Tolerance for Disagreement}

behaviors(WHO 2000). The positive findings of the Dalgas- Pelish study demonstrate that teaching students about self esteem can improve the way they view themselves which in turn may help them to make better choices, achieve more, and be better equipped to face life's challenges. The crux of the experiential training program was to teach how to work in teams, learn to cooperate, learn lessons of compassion and at times let go.

The substantial increase in the level of self esteem proves the importance of group activities and effectiveness of experiential training.

\section{Resilience}

It was hypothesized that there would be an overall increase in resilience after the experiential training which was focusing on providing an encouraging and non-evaluative environment where participants are allowed to freely interact and express themselves. A significant $t$-value ( $t=3.12$, $\mathrm{p}<.01$ ) between the pre and post test results does indeed validate this hypothesis.

According to Engelhardt and Simmons (2002b) Today's high-velocity and competitive markets apply added pressure to adapt rapidly and perform at high levels. This adaptive capacity allows for a higher tolerance for change (Bennett \&Bennett, 2004). Organizational resilience is sometimes considered as the degree of flexibility or rigidity of an organization's culture in response to change (Schien, 2004). In other words, organizational resilience is a collective adaptive capacity for change. If future change is to occur in organizations, it will likely come through resilient teams (Chan, et al., 2003). Leaders may develop competencies of resilience in teams. Because preparation reduces uncertainty, leaders may be able to develop competencies of resilience in their teams and organizations, in a way of being prepared for the unexpected or in omnia paratus, prepared for all things. While teams may not be able to anticipate every adversity, teams can develop resilience to adapt and change to new conditions.

\section{Tolerance for disagreement}

Tolerance for disagreement scores indicates that there is a significant increase in the levels of tolerance for disagreement. Here also $t$-value is significant $(t=6.40, p<.01$ ), thus verifying the third hypothesis as well.

Individuals differ in the extent to which they can tolerate disagreement, and thus avoid entering into conflict. When disagreement is taken personally conflict is created. McCroskey (1992) further explains the difference in people with both low and high tolerance for disagreement by arguing that "people with high tolerance for disagreement are relatively conflict resistant whereas people with low tolerance for disagreement are highly conflict prone “. Thus tolerance for disagreement has been redefined as "the amount of disagreement an individual can tolerate before he or she perceives the existence of conflict in a relationship”. (McCrosky, Richmound 


\section{Effect of Experiential Learning on Self-Esteem, Resilience and Tolerance for Disagreement}

1992, p.125) group activities increased the affinity amongst the group members eventually leading to an increase in tolerance for disagreement.

\section{CONCLUSION}

The reported growth in self esteem, resilience and tolerance for disagreement proves the effectiveness of experiential training programs. In a nutshell experiential training through teambuilding games prove to be more productive, effective, memorable and thus, more worthwhile.

Although the results of this study are encouraging, weakness in research design threaten the validity of the findings. The lack of control group does not allow for comparison with peers who did not receive the training. A true quasi experimental design with larger treatment and control groups could strengthen the design and improve the validity of the findings. The sample size is too small to effectively analyze. A larger study with more diversified population of participants would also improve the external validity of hypotheses results.

\section{Acknowledgments}

The author appreciates all those who participated in the study and helped to facilitate the research process.

\section{Conflict of Interests}

The author declared no conflict of interests.

\section{REFERENCES}

Bennett, J. M. \&Bennett, M.J.(2004). Developing intercultural sensitivity: An Integrative approach to global and domestic diversity. In D. Landis, J. M. Bennett, \& M. J. Bennett (Eds.). Handbook of intercultural training(p.p.147-165)Thousand Oaks, CA: Sage.

Brockner, J., (1998). Self esteem at work., Lexington Books, Lexington, MA.

Chan, C.C.A, Lim, L. \& Keasberry, S. K.(2003). Examining the Linkages between team learning behaviors and team performance. The Learning Organization,10(4);228-236.

Coopersmith, S.(1967). The antecedents of self-esteem., Freeman, San Francisco.

Coser, L.(1956). The functions of social conflict. New York: Free Press.

Deutsch, M(1973). The resolution of conflict: Constructive and destructive processes, New Haven, Connecticut: Yale University Press.

Engelhardt, C. S. \& Simmons, P. R.(2002b). Organizational flexibility for a changing world. Leadership and Organization Development Journal, 23(3), 113-121.

Fisher, B. A. (1970). Decision emergence; Phases in group decision making. Speech Monographs, 37, 53-66.

Horney, K. (1937). The neurotic personality of our time. New York: W.W.Norton. 


\section{Effect of Experiential Learning on Self-Esteem, Resilience and Tolerance for Disagreement}

Kilmann, R. H., \& Thomas, K.W.(1977). Developing a forced-choice measure of conflicthandling behaviour. The "MODE" instrument Educational and Psychological Measurement, 37,309-325.

Kling, K.C., Shibley Hyde, J., Showers, C.J. and Buswell, B.N.(1999). Gender differences in self-esteem: a meta analysis. Psychological Bulletin, 125, 470-500

Mack, R. W.(1966). Components of social conflict. Social Problems,12,388-397.

McCrosky, J.C., \& Wheeless,(1976). An Introduction to human communication. Boston, MA: Allyn \&Bacon

Richmond, V. P., \& McCroskey, J. C. (2001). Organizational communication for survival: Making work, work (2nd Ed.) Chapter 14. Needham Heights, MA: Allyn \& Bacon.

Rosenberg, M.(1985). Self-concept and psychological well-being in adolescence. In: R.L.Leahy, Editor, The development of the self. Academic Press. Orlando, FL, pp.205-246.

Ryff, C. (1989b). In the eye of the beholder: Views of psychological well-being among middle and old age adults. Psychology and Aging, 4, 195-210.

Schein, E. H.(2004)DEC is dead, long live DEC: Lessons on innovation, technology, and the business gene. San Francisco :Bennett-Koehler.

Teven, J. J., Richmond, V. P., \& McCroskey, J. C. (1998). Measuring tolerance for disagreement. Communication Research Reports, 15, 209-217.

Thoits, P (1999). Self identity, stress and mental health. In: C.S. Aneshensel and J. C. Phelan, Editors, Handbook of the sociology of mental health, Kluwer Academic, New York. Pp. 345-368 Chapter 17.

Watkins, C. (1974), an analytic model of conflict. Speech Monographs, 41, 1-5.

How to cite this article: M Baby (2016), Effect of Experiential Learning on Self-Esteem, Resilience and Tolerance for Disagreement, International Journal of Indian Psychology, Volume 3, Issue 4, No. 65, ISSN 2348-5396 (e), ISSN: 2349-3429 (p), DIP: 18.01.143/20160304, ISBN: 978-1-365-34680-4 